\title{
Diabetes mellitus as a risk factor for pulmonary complications after coronary bypass surgery
}

\author{
Achim H. Lauruschkat, MD, ${ }^{a}$ Bert Arnrich, MS, ${ }^{b}$ Alexander A. Albert, MD, Jörg A. Walter, PhD, ${ }^{b}$ Berthold Amann, MD, ${ }^{c}$ \\ Ulrich P. Rosendahl, MD, ${ }^{a}$ Tejas Alexander, MD, ${ }^{d}$ and Jürgen Ennker, $\mathrm{MD}^{\mathrm{a}}$
}

From the Department of Cardiac, Thoracic, and Vascular Surgery, Heart Institute Lahr/ Baden, Lahr, Germany ; the Neuroinformatics Group, Faculty of Technology, Bielefeld University, Bielefeld, Germany ${ }^{\mathrm{b}}$; the Franziskus Hospital Berlin, Berlin, Germa$n y^{c}$; and the Department of Anaesthesiology, Heart Institute Lahr/Baden, Lahr, Germany. ${ }^{\mathrm{d}}$

Received for publication Feb 5, 2007; revisions received July 4, 2007; accepted for publication July 10, 2007

Address for reprints: Achim H. Lauruschkat, MD, Department of Cardiac, Thoracic and Vascular Surgery, Heart Institute Lahr/ Baden, Hohbergweg 2, 77933 Lahr, Germany (E-mail: Lauruschkat@heart-lahr.com).

J Thorac Cardiovasc Surg 2008;135:104753

$0022-5223 / \$ 34.00$

Copyright $(\odot 2008$ by The American Association for Thoracic Surgery

doi:10.1016/j.jtcvs.2007.07.066
Objectives: In the past few years there has been increasing evidence that the respiratory function of patients with diabetes is impaired in the course of their disease. The objective of this article was to investigate whether patients with diabetes are particularly at risk of pulmonary complications during the perioperative stage of coronary bypass surgery.

Methods: The data of 8555 patients who had undergone coronary bypass operations in the years between 1996 and 2004 were analyzed. Depending on their diagnosis on admission and their fasting plasma glucose levels, these patients were classified as having "no diabetes" (fasting plasma glucose level $<126 \mathrm{mg} / \mathrm{dL}$ ), "undiagnosed diabetes" (glucose level $\geq 126 \mathrm{mg} / \mathrm{dL}$ ), "oral therapy diabetes," or "insulin-treated diabetes." The 3 diabetic groups were compared with the nondiabetic group in terms of the preoperative and postoperative characteristics.

Results: The reintubation rate among patients with undiagnosed diabetes $(4.6 \%)$ and among those with insulin-treated diabetes $(4.5 \%)$ was significantly higher than that of nondiabetic patients $(1.8 \% ; P<.01)$. The proportion of patients who required respiration for periods longer than 1 day was also significantly higher among patients with undiagnosed diabetes $(9.9 \%)$ and those with insulin-treated diabetes $(8.6 \%)$ than among the nondiabetic patients $(4.8 \% ; P<.01)$. The regression models show that unidentified diabetes and insulin-treated diabetes constitute independent risk factors for perioperative pulmonary complications.

Conclusions: Patients with undiagnosed and insulin-treated diabetes have a higher risk of having pulmonary complications in the perioperative course of coronary bypass operations than do nondiabetic patients. These results may be explained if one considers the lung as another target organ of the diabetic disease.

$\mathrm{E}$ arlier investigations involving lung function in individuals with type 1 diabetes suggested that the lung may also be a target organ of the diabetic disease. Schuyler and associates ${ }^{1}$ showed, for instance, that lung elastic recoil was reduced in patients with type 1 diabetes. Sandler and colleagues ${ }^{2}$ reported reduced lung elasticity, a lower carbon monoxide transfer capacity, and a smaller pulmonary capillary blood volume. In the following years, the concept of the lung as a target organ of diabetic micro-angiopathy gained further attention. Sandler ${ }^{3}$ concluded that the lung ought to be considered as a potential target organ of diabetes mellitus, but they also found that the pathophysiologic changes observed were relatively minor and that, as a result, no clear clinical implications of these findings could be determined. Later investigations into the lung transfer capacity for carbon monoxide ${ }^{4}$ and postmortem histopathologic studies ${ }^{5}$ provided further evidence that the lung is a target organ of micro-angiopathy in both type 1 and type 2 diabetes. It was shown, however, that the simple pulmonary function tests underrated the prevalence and the extent of lung dysfunction in patients with diabetes.

Cardiac surgeons have been familiar for quite some time with what is known as "pulmonary injury," particularly during extracorporeal circulation, ${ }^{6,7}$ with the causes 


\section{Abbreviations and Acronyms}

$\mathrm{FEV}_{1}=$ forced expiratory volume in 1 second

$\mathrm{FPG}=$ fasting plasma glucose

$\mathrm{FVC}=$ forced vital capacity

ICU = intensive care unit

seen as (1) contact of the blood constituents with the artificial surface of the tube system, (2) ischemia/reperfusion damage, (3) endotoxemia, and (4) operative trauma. Proven effects include the activation of the complementary system, the activation of neutrophils, the adhesion of neutrophils to the endothelium of lung vessels, and endothelial damage caused by proteases. Lung damage after cardiopulmonary bypass also causes higher lung permeability, higher pulmonary vascular resistance, and changes in lung surfactants. Subsequent effects include pulmonary edema, alveolar protein accumulation, and the increased sequestration of inflammatory cells, ${ }^{7}$ which, in turn, impairs pulmonary function.

Against this background, the question arises whether patients with diabetes are particularly at risk of pulmonary complications in the perioperative course of coronary bypass operations.

\section{Materials and Methods}

The study included 8555 patients who had undergone elective coronary bypass operations at the Heart Institute Lahr/Baden in the period between January 1996 and December 2004. Patients who underwent emergency interventions, combined procedures, and "redo" operations were excluded from the study. Patient care, both at the operative and the postoperative stages, followed the standardized guidelines of our hospital. Only membrane oxygenators were used in the extracorporeal circulation, with blood cardioplegia used as the cardioplegic solution. To avoid thermal damage of the phrenic nerve, we used no additional external topical cooling of the myocardium. All patients underwent hourly control of plasma glucose during the operation and the first 36 hours postoperatively, followed by 6 hourly plasma glucose readings until hospital discharge. Therapeutic aim was to achieve near-normal glycemia. Continuous intravenous insulin infusions during the operation and the immediate postoperative phase, as well as subcutaneous insulin application added by oral antidiabetic therapy in the later phase, were used to achieve this goal. Blood glucose control with continuous intravenous insulin infusion was initiated at a threshold level of $150 \mathrm{mg} / \mathrm{dL}$. Insulin was started in the operating room before sternotomy and after induction of anesthesia. The perioperative and postoperative blood glucose target was 100 to $150 \mathrm{mg} / \mathrm{dL}$, and insulin dose was adapted according to the Portland protocol. $^{8}$

For each patient included in the present study, 32 preoperative characteristics and 8 postoperative progress values were used from the consolidated database of our Data Mart system. ${ }^{9}$ The data were based on information from anesthesiologic and cardiac surgical quality assurance figures and clinical chemistry laboratory results.

\section{Definitions}

The following definitions, essentially applied in analogy with the EuroSCORE, ${ }^{10}$ were used for the risk factors investigated:

- Peripheral vascular disease: claudication, previous or planned intervention involving the arteries of the limbs

- Carotid disease: carotid occlusion or greater than 50\% stenosis, previous or planned intervention on the carotids

- Neurologic dysfunction: severely affecting ambulation or day-to-day functioning

- Chronic obstructive pulmonary disease: long-term use of bronchodilators or steroids for lung disease

- Pulmonary hypertension: systolic pulmonary artery pressure greater than $60 \mathrm{~mm} \mathrm{Hg}$

- Recent myocardial infarction: infarction within 90 days

- Unstable angina: rest angina requiring intravenous nitrates until arrival in the anesthetic room; patients who were not fully without symptoms under intravenous nitrate medication were declared as "emergency cases" and excluded from the study

- Stroke: a new focal neurologic deficit or coma lasting more than 24 hours, associated with computed tomographic demonstration or recent ischemic cerebral lesion

- Cerebral dysfunction: in comparison with the preoperative status, abnormalities in behavior and temporal and spatial disorientation that are also clinically conspicuous without specific psychiatric examinations.

Diabetes was diagnosed by the current recommendations of the American Diabetes Association ${ }^{11}$ : The determination of the diabetes status in epidemiologic studies is based on the measurement of the fasting plasma glucose level (FPG $\geq 126 \mathrm{mg} / \mathrm{dL}[7.0 \mathrm{mmol} / \mathrm{L}]$ ). Patients admitted with a previous diagnosis of "diabetes mellitus" were classified either as having "oral therapy diabetes" or "insulin-treated diabetes" in line with their previous therapies. The remaining patients were classified in accordance with their FPG level as having either "undiagnosed diabetes" (FPG $\geq 126 \mathrm{mg} /$ $\mathrm{dL}$ ) or "no diabetes" (FPG $<126 \mathrm{mg} / \mathrm{dL}$ ). These groups of patients were compared in terms of their preoperative characteristics and risk factors and the data of their postoperative progress.

\section{Statistical Analysis}

Univariate comparisons among the 4 patient groups investigated (no diabetes, undiagnosed diabetes, oral therapy diabetes, and insulintreated diabetes) were performed by the $\chi^{2}$ test for categorical variables and the Mann-Whitney test for continuous variables (SPSS 12.0; SPSS, Inc, Chicago, Ill). Stepwise logistic regression was used to determine the predictors of the hospital outcomes of interest by minimizing the so-called Akaike Information Criterion.

All baseline attributes and three additional dichotomous indicator variables encoding the diabetes status were initially used in the regression tasks. To obtain a nondiabetic reference group, we defined the three indicator variables as follows: (1) undiagnosed diabetes mellitus $=1$ for patients with undiagnosed diabetes, 0 otherwise; (2) oral therapy diabetes mellitus $=1$ for patients with orally treated diabetes, 0 otherwise; and (3) insulin-treated diabetes mellitus $=1$ for insulin-treated diabetes, 0 otherwise. In cases in which only one or two indicator variables were significant in the final model, the remaining one or two variables were forced into the model. Model discrimination was evaluated by the area under the receiver operating characteristic curve. 


\section{Results}

The distribution of the patients over the different patient groups involved in the study and the initial parameters fully included in the regression analysis are shown in Table 1. Hospital outcome is shown in Table 2.

Patients with undiagnosed diabetes are significantly more often in need of resuscitation than the other patient groups. Postoperative renal failure requiring dialysis occurs significantly more often among undiagnosed and insulin-treated diabetic patients than in nondiabetic patients with coronary disease. Perioperative strokes occur more frequently among insulin-treated diabetic patients than in nondiabetic patients. Also, diabetic patients more frequently experience conspicuous mental disturbance in the postoperative period. Patients with undiagnosed diabetes and insulin-treated diabetes are significantly more often in need of reintubation in the postoperative period than nondiabetic patients (no diabetes $1.8 \%$ vs undiagnosed diabetes $4.6 \%$ vs oral therapy diabetes $2.3 \%$ vs insulin-treated diabetes $4.5 \%$ ). The proportion of patients who require ventilation for longer than 1 day is also highest

TABLE 1. Baseline characteristics for the 4 patient groups

\begin{tabular}{|c|c|c|c|c|}
\hline & $\begin{array}{l}\text { No diabetes } \\
\text { (n = 5477) }\end{array}$ & $\begin{array}{l}\text { Undiagnosed diabetes } \\
\qquad(\mathrm{n}=372)\end{array}$ & $\begin{array}{l}\text { Oral therapy diabetes } \\
\qquad(n=1697)\end{array}$ & $\begin{array}{l}\text { Insulin-treated diabetes } \\
\qquad(\mathrm{n}=1009)\end{array}$ \\
\hline \multicolumn{5}{|l|}{ Demographic profile } \\
\hline Age (y) & $65.05 \pm 9.58$ & $66.20 \dagger \pm 9.53$ & $66.54^{*} \pm 8.30$ & $66.56^{*} \pm 8.40$ \\
\hline Female sex $(\%)$ & 21.3 & 25.8 & $24.9 *$ & $39.5^{*}$ \\
\hline Body mass index $\left(\mathrm{kg} / \mathrm{m}^{2}\right)$ & $27.44 \pm 3.89$ & $27.85 \dagger \pm 3.73$ & $28.57^{*} \pm 4.11$ & $28.87^{*} \pm 4.72$ \\
\hline \multicolumn{5}{|l|}{ Medical history } \\
\hline Hypertension (\%) & 75.0 & 75.3 & $83.3^{*}$ & $86.6^{*}$ \\
\hline Peripheral vascular disease (\%) & 8.1 & $11.8 \dagger$ & $10.8^{*}$ & $21.1^{*}$ \\
\hline Carotid disease (\%) & 9.1 & 10.8 & $12.2^{*}$ & $13.4^{*}$ \\
\hline Past stroke $(\%)$ & 6.4 & 5.1 & $8.6^{*}$ & $10.7^{*}$ \\
\hline Neurologic dysfunction (\%) & 6.1 & 5.6 & $8.0^{*}$ & $13.1^{*}$ \\
\hline COPD $(\%)$ & 19.4 & 20.2 & $24.5^{*}$ & $28.4^{*}$ \\
\hline Pulmonary hypertension (\%) & 2.3 & 1.6 & 2.7 & 3.2 \\
\hline Recent myocardial infarction (\%) & 23.2 & $28.0 \dagger$ & $26.9^{*}$ & $26.7, P<.05$ \\
\hline Unstable angina (\%) & 10.1 & $14.2 \dagger$ & 10.0 & 8.4 \\
\hline NYHA class IV (\%) & 5.9 & 7.8 & 6.1 & $9.1^{*}$ \\
\hline Ejection fraction $30 \%-50 \%(\%)$ & 29.0 & 31.2 & $37.7^{*}$ & $39.6^{*}$ \\
\hline Ejection fraction $<30 \%(\%)$ & 3.3 & 2.4 & $5.2^{*}$ & $5.6^{*}$ \\
\hline \multicolumn{5}{|l|}{ Angiographic characteristics } \\
\hline One-vessel disease (\%) & 10.0 & $6.5 \dagger$ & $6.7^{*}$ & $5.3^{*}$ \\
\hline Two-vessel disease (\%) & 32.8 & 30.6 & $29.6 \dagger$ & $28.1^{*}$ \\
\hline Three-vessel disease (\%) & 50.4 & $59.1^{*}$ & $57.5^{*}$ & $60.3^{*}$ \\
\hline Main stem disease $(\%)$ & 18.5 & 17.2 & 16.7 & $15.5 \dagger$ \\
\hline \multicolumn{5}{|l|}{ Laboratory parameters } \\
\hline Hemoglobin (g/dL) & $13.90 \pm 1.51$ & $13.92 \pm 1.61$ & $13.80 \dagger \pm 1.58$ & $13.19^{*} \pm 1.61$ \\
\hline Erythrocytes $\left(10^{6} / \mu \mathrm{L}\right)$ & $4.51 \pm 0.50$ & $4.53 \pm 0.54$ & $4.51 \pm 0.52$ & $4.36^{*} \pm 0.54$ \\
\hline Thrombocytes $\left(10^{3} / \mu \mathrm{L}\right)$ & $233.4 \pm 67.6$ & $237.2 \pm 69.6$ & $230.7 \pm 65.8$ & $236.4 \pm 70.4$ \\
\hline Leukocytes $\left(10^{3} / \mu \mathrm{L}\right)$ & $7.59 \pm 2.28$ & $8.08^{*} \pm 3.12$ & $7.74^{*} \pm 2.11$ & $8.08^{*} \pm 2.37$ \\
\hline Total cholesterol (mg/dL) & $201.9 \pm 44.6$ & $210.6^{*} \pm 48.9$ & $197.7^{*} \pm 46.9$ & $190.9^{*} \pm 47.2$ \\
\hline Creatinine (mg/dL) & $1.13 \pm 0.51$ & $1.23^{*} \pm 0.61$ & $1.16^{*} \pm 0.46$ & $1.31^{*} \pm 0.76$ \\
\hline Urea $(\mathrm{mg} / \mathrm{dL})$ & $38.88 \pm 14.7$ & $44.15^{*} \pm 23.9$ & $42.63^{*} \pm 17.5$ & $50.67^{*} \pm 25.4$ \\
\hline Creatine kinase (U/L) & $50.13 \pm 72.7$ & $45.47^{*} \pm 65.2$ & $51.85^{*} \pm 197$ & $58.52 \dagger \pm 105$ \\
\hline \multicolumn{5}{|l|}{ Medications } \\
\hline ACE inhibitors (\%) & 49.1 & 45.2 & $59.7^{*}$ & $64.3^{*}$ \\
\hline Aspirin (\%) & 25.0 & 24.2 & 23.3 & $19.4^{*}$ \\
\hline Beta blockers (\%) & 71.2 & $66.1, P<.05$ & $67.6^{*}$ & $64.8^{*}$ \\
\hline Diuretics (\%) & 18.1 & 20.4 & $28.8^{*}$ & $38.1^{*}$ \\
\hline Nitrates (\%) & 58.9 & 61.8 & 59.5 & $55.2 \dagger$ \\
\hline
\end{tabular}

Baseline characteristics for the 4 patient groups in percent (\%) or as group average (with units). Tests on group equivalence are performed by the $\chi^{2}$ test for categorical data and for continuous variables by the Mann-Whitney test (for the latter, standard deviations [ \pm SD] are given with the same units). COPD, Chronic obstructive pulmonary disease; NYHA; New York Heart Association; $A C E$, angiotensin-converting enzyme. Significant difference to No diabetes group: ${ }^{*} P<.01 ; \dagger P<.05$. 
TABLE 2. Hospital outcome

\begin{tabular}{lcccc}
\hline \multicolumn{1}{c}{ Outcome } & No diabetes & Undiagnosed diabetes & Oral therapy diabetes & Insulin-treated diabetes \\
\hline Cardiopulmonary resuscitation (\%) & 1.4 & $4.3^{*}$ & 1.5 & 1.8 \\
Renal failure, dalysis (\%) & 1.4 & $3.5^{*}$ & 1.9 & $8.9^{*}$ \\
Stroke (\%) & 1.2 & 1.9 & 1.8 & $2.5^{*}$ \\
Cerebral dysfunction (\%) & 4.5 & 6.2 & $6.5^{*}$ & $9.8^{*}$ \\
Reintubation (\%) & 1.8 & $4.6^{*}$ & 2.3 & $5.5^{*}$ \\
Ventilation time > 1 d (\%) & 4.8 & $9.9^{*}$ & $31.8^{*}$ & $3.6^{*}$ \\
ICU stay > 3 d (\%) & 26.9 & 28.8 & 1.4 & $1.4^{*}$ \\
30-d mortality (\%) & 0.8 & $2.7^{*}$ & \\
\hline
\end{tabular}

ICU, Intensive care unit. Significant difference to No diabetes group: ${ }^{*} P<.01 ; \dagger P<0.05$.

among these patient groups (no diabetes $4.8 \%$ vs undiagnosed diabetes $9.9 \%$ vs oral therapy diabetes $5.4 \%$ vs insulin-treated diabetes $8.6 \%$ ). On average, diabetic patients with coronary disease spend longer periods of time in the intensive care unit (ICU) than patients without diabetes and have a significantly higher 30-day mortality rate, with the highest mortality being found in the group of patients with undiagnosed diabetes.

Table 3 shows the two resulting regression models in which undiagnosed diabetes, oral therapy diabetes, and insulin-treated diabetes are listed. The results show that undiagnosed diabetes and insulin-treated diabetes are independent risk factors for a longer period of ventilation and for more frequent reintubation at the postoperative stage.

\section{Discussion}

Even after accounting for other risk factors such as age, body mass index, and pre-existing chronic obstructive pulmonary disease, the significantly longer ventilation time and the higher frequency of reintubation among diabetic patients at the postoperative stage is conspicuous. These results may be explained if one considers that the respiratory function of diabetic patients is also impaired in the course of their disease.

\section{Pathophysiology of Lung Dysfunction in Patients With Diabetes}

The pulmonary function of patients with diabetes has been the subject of numerous studies. Walter and associates, ${ }^{12}$ for instance, were able to show in the Framingham Heart Study (1971-1975) that unidentified and known diabetes mellitus was associated with reduced forced expiratory volume in 1 second $\left(\mathrm{FEV}_{1}\right)$ and forced vital capacity (FVC) values. The study by McKeever and coworkers ${ }^{13}$ and the data of the Copenhagen City Heart Study ${ }^{14}$ confirm these results. The latter study also showed that the most significant impairment of pulmonary function is found among patients with insulin-treated diabetes. These results suggest that pulmonary function declines as the diabetic disorder progresses over time, with some evidence to suggest that disturbances of pulmonary function appear at quite an early stage of the disease, even before it is apparent in clinical terms. The results of the British Women's Heart and Health Study (1999-2001) ${ }^{15}$

TABLE 3. Logistic regression analysis for the two outcomes

\begin{tabular}{|c|c|c|c|c|c|c|}
\hline & Diabetes status & No. of events & Crude OR & Adjusted OR & $95 \% \mathrm{Cl}$ & $\boldsymbol{P}$ \\
\hline \multirow[t]{3}{*}{ Reintubation* } & Undiagnosed DM & 17 & 2.55 & 1.96 & $1.14-3.49$ & .02 \\
\hline & Oral therapy DM & 39 & 1.25 & 1.06 & $0.72-1.54$ & .78 \\
\hline & Insulin-treated DM & 45 & 2.48 & 1.63 & $1.11-2.39$ & .01 \\
\hline \multirow[t]{3}{*}{ Ventilation time $>1 \mathrm{~d} \dagger$} & Undiagnosed DM & 37 & 2.17 & 1.84 & $1.26-2.69$ & $<.01$ \\
\hline & Oral therapy DM & 91 & 1.11 & 0.94 & $0.73-1.21$ & .61 \\
\hline & Insulin-treated DM & 87 & 1.86 & 1.33 & $1.01-1.74$ & .04 \\
\hline
\end{tabular}

Logistic regression analysis for the two outcomes "Reintubation" and "Ventilation time $>1 \mathrm{~d}$." For each outcome the crude OR (resulting from simple logistic models where only the indicator variables "Undiagnosed DM," "Oral therapy DM," and "Insulin-treated DM" were included) and the adjusted OR with additional covariates and the area under the receiver operating characteristic curve given in the footnote, are presented. The Cls and $P$ values correspond to the adjusted models, respectively. $O R, 0$ dds ratio; $C l$, confidence interval (for the adjusted $\mathrm{OR}$ ); $D M$, diabetes mellitus. *Further covariates $i$ of fully adjusted model: $\beta$-blockers $(0.7,0.52-0.94)$, left ventricular ejection fraction (LVEF) $30 \%$ to $50 \%(1.42,1.05-1.93)$, LVEF $<30 \%\left(2.58,1.54-4.32^{*}\right)$, female sex $(1.38,1.01-$ $1.88)$, leukocytes $(1.05,1.01-1.1)$, urea $\left(1.02,1.01-1.02^{*}\right)$, unstable angina $(1.62,1.09-2.39)$. In parenthesis exp(beta ${ }_{i}$ coefficient) - equivalent to $0 \mathrm{R}_{i}$ for categorical attributes, its $95 \% \mathrm{Cl}$, and significance indicator $\ddagger$ for $P<0.01$; area under the receiver operating characteristic curve: 0.67 . $\dagger$ Further covariates $i$ of fully adjusted model: age $(1.04,1.02-1.05 \ddagger)$, past stroke $(1.79,1.35-2.39 \ddagger)$, angiotensin-converting enzyme inhibitors $(0.82,0.68-1.0)$, diuretics $(1.3,1.05-1.62)$, recent myocardial infarction $(0.79,0.63-0.99)$, LVEF $30 \%$ to $50 \%(1.43,1.16-1.76 \ddagger)$, LVEF $<30 \%(3.44,2.45-4.83 \ddagger)$, leukocytes $(1.09,1.05-1.12 \ddagger)$, urea $(1.01,1.0-1.01 \ddagger)$, unstable angina $(1.56,1.19-2.04 \ddagger)$. In parenthesis exp(beta ${ }_{i}$ coefficient) - equivalent to $0 \mathrm{R}_{i}$ for categorical attributes, its $95 \% \mathrm{Cl}$, and significance indic ator $\ddagger$ for $P<.01$; area under the receiver operating characteristic curve: 0.69 . 
show that both insulin resistance and clinically manifest diabetes mellitus are accompanied by reduced $\mathrm{FEV}_{1}$ and FVC values. Longitudinal studies have shown that the most pronounced impairments of pulmonary function $\left(\mathrm{FEV}_{1}, \mathrm{FVC}\right)$ were found among patients in whom diabetes had developed during the period of observation. ${ }^{16}$ For clinically manifest diabetes mellitus, it appears that stabilizing the blood glucose level to near-normal values is of paramount importance. Authors who had investigated the quality of the metabolic management over several years in patients with type 1 diabetes reported that normoglycemic patients show significantly fewer impairments of pulmonary function. ${ }^{17}$

Evidence for a reduction in the carbon monoxide diffusion capacity has been shown both for patients with type 1 diabetes $^{4}$ and for individuals with type 2 diabetes, ${ }^{18}$ with some of these diffusion disturbances associated with signs of a diabetic nephropathy (albuminuria/proteinuria). ${ }^{4,18}$ The histomorphologic correlate of these findings has been described in closer detail by Weynand and colleagues. ${ }^{5}$ Using autopsy findings, the authors were able to show that the basal membranes of the renal glomeruli, the alveolar epithelium, and the capillary lung endothelium were thickened in patients with diabetes. ${ }^{5}$

It should also be kept in mind that patients with diabetes have specific neurologic and neuromuscular dysfunctions. The results of various studies show, for instance, that diabetic patients have a reduced respiratory drive under hypoxic conditions. ${ }^{19}$ Studies involving individuals with type 1 diabetes also suggest that the efficiency of the respiratory muscles is significantly lower than in healthy test persons. With muscle power maintained, it appears that it is the muscle performance that is particularly impaired. ${ }^{20}$

The results of the present study also show that neurologic damage and a state of confusion occur significantly more often among diabetic patients during the postoperative stage of coronary bypass operations. Experience shows that these patients often take longer to be weaned from the respirator and often have difficulty later in following the routine postoperative breathing exercises under the instruction of a trained physiotherapist.

\section{Pathophysiology of Lung Dysfunction in the Postoperative Course}

The unique conditions of postoperative progress after coronary bypass operations should be noted in this context. More than any other organ, the lungs are adversely affected after cardiac surgical interventions accompanied by extracorporeal circulation, although these dysfunctions tend to be weak and transient. These impairments of pulmonary function have a number of different causes. They are partly due to the suspended or strongly reduced lung perfusion during the period of extracorporeal circulation, which, in turn, causes lower shear forces in the pulmonary capillaries and the activation of neutrophil granulocytes-particularly since the neutrophils appear to be especially sensitive to shear forces. The permeability of the alveolar-capillary barrier increases and macromolecules migrate into the pulmonary interstitial space and the alveoli and, therefore, are able to promote the development of pulmonary edema. A more extensive pulmonary edema can also develop under low or normal left atrial pressure, undoubtedly caused by changes in the pulmonary venous and capillary permeability, the causes of which are as yet not fully understood. This phenomenon appears to be more pronounced in older patients. ${ }^{21}$ However, more or less distinct signs of pulmonary dysfunction are found in almost all patients.

In the course of an uncomplicated postoperative recovery, patients usually cough up thick tracheobronchial secretions between 24 and 72 hours after the intervention. Symptoms such as dyspnea and tachypnea tend to subside with the onset of this productive cough. At this point, the protein-rich liquid that has remained in the alveoli and the interstitial space since the use of cardiopulmonary bypass is presumably carried by ciliary movement from the terminal bronchioli to the larger respiratory tracts, from which it can be coughed out. The lung volumes are usually reversibly reduced after a cardiac surgical intervention, in particular vital capacity and the total lung volume. ${ }^{22}$ This is presumably due to the common effects of small, multiple atelectatic regions, the occasional collapse of the left lower lobe, to pulmonary edema and pleural effusions, and to lower inspiratory power. Blood gas analyses, therefore, show that arterial oxygen tensions are clearly reduced during the postoperative stage of bypass operations. In general, these values reach their lowest point on the second postoperative day and do not return to the preoperative level until 1 week or more later. ${ }^{23}$

Guazzi and colleagues ${ }^{24}$ showed that cardiac insufficiency and diabetes mellitus result in similar disturbances of pulmonary function, which suggests an additive or even a synergistic effect. Under the conditions of this comorbidity, the frequency and the extent of gas exchange disturbance were significantly higher, with the cardiac insufficiency appearing to unmask the diabetic micro-angiopathy of the lungs. The outcome of our study could indicate that the above-described pathophysiologic changes after extracorporeal circulation (eg, pulmonary edema and alveolar protein accumulation) could also contribute toward the unmasking of the diabetic lung disorder.

\section{Discussion of the Different Outcome Among the Examined Patient Groups}

Remarkably, we encountered the highest risk of pulmonary complications in the perioperative course of coronary bypass operations in the group of patients with newly detected diabetes, keeping in mind that these patients (as shown in Table 1) have a characteristic risk profile but, unlike the patients with known diabetes, have not been appropriately treated. ${ }^{25}$ The more favorable results of the patients receiving oral therapy could conceivably be seen as evidence that the improvement 
in metabolic management of the patients with diagnosed diabetes has resulted in a lower intensity in the diabetic micro-angiopathy of the target organ lung in the course of the years. It should also be noted that there have been significant preoperative differences in the patients' drug therapy. The lowest number of patients treated with angiotensin-converting enzyme inhibitors is, for instance, found in the group of patients with newly detected diabetes. Guazzi and associates ${ }^{26,27}$ also demonstrated in several studies that angiotensin-converting enzyme inhibitors in patients with cardiac insufficiency significantly improve the conductivity of the alveolar-capillary membrane. The effective mechanisms under discussion include the inhibition of the angiotensin-mediated collagen synthesis and the activation of the prostaglandin system, which also reduces collagen metabolism. ${ }^{27}$ These effects could conceivably lead to the regression of the structural changes in the diabetes-related thickening of the alveolar-capillary membrane and therefore to an improvement in the membranous gas exchange.

The incidence of postoperative pulmonary complications was significantly higher among the insulin-treated patients in our study than among the oral therapy diabetic patients. Inasmuch as insulin therapy is usually preceded by a period of treatment involving oral antidiabetic agents, one may assume that the insulin-treated patients have had diabetes for longer periods than the orally treated patients. Our data may therefore suggest that, as the duration of the underlying diabetes increases, there are more pronounced morphologic changes of the lungs which, under the additional stress caused by the pathophysiologic changes after cardiopulmonary bypass, could result in an increase in the occurrence of pulmonary complications.

The issue of the risk factors for pulmonary complications during the perioperative stage of coronary bypass operations also entails some important aspects of health economy. Longer periods of ventilation lead to longer ICU hospitalization periods, fewer hospital beds, and higher public health costs. If the current demographic trends continue, the near future will see an increasing burden on the public health system caused by the more frequent ICU bed use by a growing number of older (and diabetic) patients. In view of these developments, it seems imperative to identify patients with a higher risk of postoperative pulmonary complications as early as in the preoperative stage to allow the development of preventive measures and the allocation of appropriate funds. Although pulmonary function tests and blood gas analyses are often carried out in the course of preoperative examinations, there is insufficient evidence to recommend the routine use of these tests. ${ }^{28}$ Preoperative pulmonary function tests in patients who underwent coronary bypass operations had no predictive merits with regard to postoperative pulmonary complications. ${ }^{29}$ The recommendation for the preoperative evaluation therefore focuses on a risk stratification model which - on the strength of the results of the present studyshould definitely include the differentiated diabetes status.
Hulzebos and colleagues ${ }^{30}$ were able to show that the prophylactic training of inspiratory muscles before coronary bypass operations can help to avoid pulmonary complications in the postoperative course. The outcome of the present study suggests that it is the diabetic coronary patients, in particular, who might benefit from preoperative and intensive respiratory training before undergoing bypass operations. Specific physiotherapeutic efforts involving selected highrisk patients could therefore help to avoid pulmonary complications in the perioperative course.

We thank Sarah Ganter, Renate Böhmer, Peter Mühlecker, and Ulrike Ritzau (Heart Institute Lahr/Baden) for expert help with data collection.

\section{References}

1. Schuyler M, Niewoehner D, Inkley S, Kohn R. Abnormal lung elasticity in juvenile onset diabetes mellitus. Am Rev Respir Dis. 1976;113:37-41.

2. Sandler M, Bunn AE, Stewart RI. Cross-section study of pulmonary function in patients with insulin-dependent diabetes mellitus. Am Rev Respir Dis. 1987;135:223-9.

3. Sandler M. Is the lung a "target organ" in diabetes mellitus? Arch Intern Med. 1990;150:1385-8.

4. Ljubic S, Metelko Z, Car N, Roglic G, Drazic Z. Reduction of diffusion capacity for carbon monoxide in diabetic patients. Chest. 1998;114: 1033-5.

5. Weynand B, Jonckheere A, Frans A, Rahier J. Diabetes mellitus induces a thickening of the pulmonary basal lamina. Respiration. 1999;66:14-9.

6. Asimakopoulos G, Smith PL, Ratnatunga CP, Taylor KM. Lung injury and acute respiratory distress syndrome after cardiopulmonary bypass. Ann Thorac Surg. 1999;68:1107-15.

7. Ng CSH, Wan S, Yim APC, Arifi AA. Pulmonary dysfunction after cardiac surgery. Chest. 2002;121:1269-77.

8. Zerr KJ, Furnary AP, Grunkemeier GL, Bookin S, Kanhere V, Starr A. Glucose control lowers the risk of wound infection in diabetics after open heart operations. Ann Thorac Surg. 1997;63:356-61.

9. Arnrich B, Walter J, Albert A, Ennker J, Ritter H. Data Mart based research in heart surgery: challenges and benefit. Medinfo. 2004; 11(Pt 1):8-12.

10. Nashef SAM, Roques F, Michel P, Gauducheau E, Lemeshow S, Salamon R, for the EuroSCORE study group. European System for Cardiac Operative Risk Evaluation (EuroSCORE). Eur J Cardiothorac Surg. 1999;16:9-13.

11. American Diabetes Association. Diagnosis and classification of diabetes mellitus. Diabetes Care. 2004;27(Suppl.1):S11-4.

12. Walter RE, Beiser A, Givelber RJ, O'Connor GT. Association between glycemic state and lung function. The Framingham heart study. Am J Resp Crit Care Med. 2003;167:911-6.

13. McKeever TM, Weston PJ, Hubbard R, Fogarty A. Lung function and glucose metabolism: an analysis of data from the third national health and nutrition examination survey. Am J Epidemiol. 2005;161:546-56.

14. Lange P, Groth S, Kastrup J, Mortensen J, Appleyard M, Nyboe J, et al. Diabetes mellitus, plasma glucose and lung function in a cross-sectional population study. Eur Respir J. 1989;2:14-9.

15. Lawlor D, Ebrahim S, Davey Smith G. Associations of measures of lung function with insulin resistance and type 2 diabetes: findings from the British Women's Heart and Health Study. Diabetologia. 2004;47: 195-203.

16. Lange P, Groth S, Mortensen J, Appleyard M, Nyboe J, Schnohr P, et al. Diabetes mellitus and ventilatory capacity: a five year follow-up study. Eur Respir J. 1990;3:288-92.

17. Niranjan V, McBrayer DG, Ramirez LC, Raskin P, Hsia CC. Glycemic control and cardiopulmonary function in patients with insulin-dependent diabetes. Am J Med. 1997;103:504-13. 
18. Guvener N, Tutuncu NB, Akcay S, Eyuboglu F, Gokcel A. Alveolar gas exchange in patients with type 2 diabetes mellitus. Endocr J. 2003;50: 663-7.

19. Weisbrod CJ, Eastwood PR, O'Driscoll G, Green DJ. Abnormal ventilatory responses to hypoxia in Type 2 diabetes. Diabetes Med. 2005; 22:563-8.

20. Heimer D, Brami J, Lieberman D, Bark H. Respiratory muscle performance in patients with type 1 diabetes. Diabetes Med. 1990;7: 434-7.

21. Maggart M, Stewart S. The mechanisms and the management of noncardiogenic pulmonary edema following cardiopulmonary bypass. Ann Thorac Surg. 1987;43:231-6.

22. Estenne M, Yernault JC, De Smet JM, De Troyer A. Phrenic and diaphragm function after coronary artery bypass grafting. Thorax. 1985;40:293-9.

23. Taggart DP, El-Fiky M, Carter R, Bowman A, Wheatley DJ. Respiratory dysfunction after uncomplicated cardiopulmonary bypass. Ann Thorac Surg. 1993;56:1123-8.

24. Guazzi M, Brambilla R, Pontone G, Agostoni P, Guazzi MD. Effect of non-insulin-dependent diabetes mellitus on pulmonary function and exercise tolerance in chronic congestive heart failure. Am J Cardiol. 2002;89:191-7.
25. Lauruschkat AH, Arnrich B, Albert AA, Walter JA, Amann B, Rosendahl UP, et al. Prevalence and risks of undiagnosed diabetes mellitus in patients undergoing coronary artery bypass grafting. Circulation. 2005;112:2397-402.

26. Guazzi M, Melzi G, Marenzi GC, Agostoni P. Angiotensin-converting enzyme inhibition facilitates alveolar-capillary gas transfer, and improves ventilation/perfusion coupling in patients with left ventricular dysfunction. Clin Pharmacol Ther. 1999;65:319-27.

27. Guazzi M, Agostoni P. Angiotensin-converting enzyme inhibition restores the diffusing capacity for carbon monoxide in patients with chronic heart failure by improving the molecular diffusion across the alveolar capillary membrane. Clin Sci. 1999;96:17-22.

28. Yende S, Wunderink R. Validity of scoring systems to predict risk of prolonged mechanical ventilation after coronary artery bypass grafting. Chest. 2002;122:239-44.

29. Jacob B, Amoateng-Adjepong Y, Raskulasuriar S, Manthous CA, Haddad R. Preoperative pulmonary function tests do not predict outcome after coronary artery bypass. Conn Med. 1997;61:327-32.

30. Hulzebos EH, Helders PJM, Favie NJ, De Bie RA, de la Riviere AB, Van Meeteren NLU. Preoperative intensive inspiratory muscle training to prevent postoperative pulmonary complications in high-risk patients undergoing CABG surgery. JAMA. 296:1851-7.

\section{The Journal of Thoracic and Cardiovascular Surgery Conflict of Interest Policy}

To assure fairness to authors submitting work for consideration in The Journal of Thoracic and Cardiovascular Surgery, a mechanism exists for managing conflicts of interest. The editor and each of the section editors complete a "Conflict of Interest" form that identifies any and all relationships with commercial and other academic entities. When the editor has a potential conflict because of a relationship with another entity or author, the editor appoints an alternate editor from among the section editors or editorial board members who assumes the entire responsibility for final decisions on the manuscript in question. The editor does not read the reviews that are submitted nor engage in discussing the manuscript prior to the final decision. When the conflict of interest involves a section editor, a "guest section editor" is appointed who fills the role normally played by the conflicted section editor. All members of the editorial board and reviewers are asked to indicate any conflict of interest when they agree to review a manuscript. 